\title{
Editionis ratio.
}

Albertus de Lauingen' e gente Bollstädt Aristotele nec ingenio nec studiis inferior, quem Magnum nominaverunt coaevi, merito admirantes eruditissimi illius viri modestiam atque pietatem summam a superbia superstitionibusque remotissimam, a posteris adeo neglectus est, ut magum eum atque fabulatorem dixerint vel peritissimi scientiarum homines, eique spurios libellos nugis fabulisque repletos incaute attribuerint.

Quo factum est ut studii naturalis in occidente antesignanum perspicacissimum, qui primus religioni christianae adsimilavit atque iniunxit sublimes illos Graecae sapientiae fontes, qui primus naturalem historiam doctrinae ecclesiasticae parem posuit, qui primus res naturales Germanicas ex arte descripsit, qui primus rerum creatarum formas ad rationes morphologicas revocare conatus est, denique qui primus atque unus historiam totius naturae per omnes explicuit partes, quasi inanem atque garrulum imitatorem et saeculum illud ipsum, quo vere Albertus eminuit, quasi solis disputationibus schola-

1 Ita Albertus, minime comes, ex oppido natali seipsum sigillo suo signavit. Conf.: Ennen et Eckertz Quellen zur Geschichte der Stadt Cöln. Vol. II. 
sticis occupatum despexerint. Neque hoc de vegetabilibus opus quamvis bis impressum viris historiam botanices diligenter describentibus Hallero Sprengelio aliis sub oculos venit, qui libellis illis spurïs ,decepti Albertum ut auctorem levissimum, botanicum ignobilem vix verbo tetigerunt.

Nostro demum saeculo subtilissini historiarum naturalium scrutatores Schneiderus Alexander de Humboldt alii nonnulli ad vera Alberti opera recurrebant, inter quos Ernestus Meyer noster ante triginta hos annos opus nostrum ne a titulo quidem satis notum primus denuo quasi detexit. Qui protinus annis 1836 et 1837 in diarii botanici "Linnaea" dicti vol. X pag. $641-741$ et vol. XI pag. $545-595$ atque fusius postea anno 1857 in Historiae suae botanices parte IV exposuit memoriae dignissima, quae ab Alberto in opere hoc genuino aut nova observata ant vetera dilucidata fuerint, nec dubitavit, Albertum ingenii acumine plantarum indigenarum peritia oculorum acie celeberrimis botanicis aequalem atque inde ab Aristotele usque ad Caesalpinum triginta saeculorum summum botanicum dicere. Quem qui refutet vix invenietur.

Simul autem Meyerus editionem operis utramque, de qua infra pag. 669 diximus, tam indiligentem et fallacem esse perspexit, ut novae editionis consilium caperet. Quam ut pararet, recentiorem editionem (J) describendam curavit, et tam ex vetustiore editione (Z) quam ex aliis libris corrigere atque emendare tentavit. Mox vero meliore consilio ad codices manuscriptos refugit, quos amicorum opera aut ipsos nactus est aut conlatos curavit. Quatuor igitur codicibus in Galliae 
et Helvetiae bibliothecis ab amicis repertis (A, B, C, V) sedulo usus est, qua de re conferas et pag. 663-665 et quae ipse Meyerus 1. c. dixit. Postquam vero, ut ipsius verbis utanur', operi huic vere aureo et nihilo secius ab ingrata posteritate abiecto, ita ut meretur, restituendo adornando omnium in usum publicando enixe incubuit; $\operatorname{mox}$ intellexit, amissa accuratiore recensione opusculi illius: De plantis, cui hoc Alberti opus inde a lib. I cap. 2 superstructum esset, nullo id pacto ad finem perduci posse. Neque huic vero negotio meram lectionem sufficere, quum tanta et tam molesta versionum discrepantia existeret, sed arte opus esse critica. Qua rite adhibita accidere posse, ut vice versa ab Alberto operi illo Pseudo-Aristotelico aliquid lucis affulgeret. Ergo etiam hunc laborem ultro suscepit. Neque recusavit negotium satis magnum quo singula verba PseudoAristotelis, quem Nicolaum Damascenum esse demonstravit, summa arte ab Alberto suis verbis intexta expiscaretur.

Cuius operis editionem accuratissimam notisque optimis illustratam postquam anno 1841 perfecit, denuo ad opus nostrum animum advertit. Locos permultos corruptos e codicibus aut coniecturis emendavit, obscuros eruditione sua ex Alberti aliorumque scriptis illustravit, plantas permultas enarravit, quae omnia in paginis insequentibus lectori in conspectu erunt. Dubitationibus autem deinde et de locis multis obscurioribus lacunosisque et de orthographia vexatus est. Primo enim sola plantarum nomina, dein vero, ne inaequalis evaderet operis orthographia, omnia operis verba non

1 Conf. Nicolai Damasceni De plantis. Recensuit E. Meyer $1 \Varangle 41$ pag. II. 
cum Jammy recentioris aevi more describenda esse sed ad modum codicum manuscriptorum duxit. Laboriose igitur scriptionem codicis Basileensis, quem optimum atque vetustissimum habuit, per libros priores quinque restituit, per ultimos duos libros, quibus ille caret, quam maxime imitatus est coniciendo. Qua in re quum minus sibi satisfaceret, opus differebat atque indefessus ad studia historica redibat, ex quibus opus illud egregium Historiae botanices inde ab anno 1854 prodiit. Quo opere quamvis totus distentus, minime tamen Alberti oblitus erat, sed et mihi opus perficiendum tradidit et ipse nummorum subsidia colligere tentavit, quibus publici iuris fieret editio nostra. Hac in re autem minus profecimus atque eodem iam anno mihi eheu! morte ereptus est dux atque amicus summopere colendus.

Tum ego de opere hoc utrum meis viribus perficiendum et quo modo evulgandum esset, diu dubitavi. Attamen pietate erga amicum motus ne diuturni eius labores perirent, neve omnino frustra essent quae nimia fiducia ille de me sibi persuasisset, neve Alberti fama opusque botanicis denuo subtraheretur, editionem pro viribus meis ad finem perduxi, quamvis nec linguae latinae tam diu neglectae satis peritus, nec in scriptis ab Alberto lectitatis codicumque scriptura enucleanda satis versatus. Atqui susceptum opus perficere non potuissem nisi favente liberaliterque adiuvante regia academia Berolinensi. Cuius auxilio praesidia operi necessaria per longos annos a Meyero assidue collecta, quum bibliotheca eius dispergeretur, acquirere potui. Mox vero opus sedulo perlustrantem vexabant me lectiones saepissime dissentientes atque evidenter vitiosae, quare 
denuo de codicibus manuscriptis a Meyero fortasse neglectis inquirere coepi. Nec frustra, tres enim in Angliae bibliothecis, quartum in Mediolanensi asservatos esse reperi. Ex Mediolanensi quidem praesidium petendum non esse, mox certiorem me fecit amicus P. Jaffé indefessus medii aevi investigator. Per regiam vero liberalitatem Angliae bibliothecas anno 1861 adire mihi licuit, ubi quum duos codices, quos infra pag. 665-666 descripsi, reliquis multo meliores, tertium nullius momenti recognovissem, comitate collegiorum, quorum fuerunt codices illi, bonum utrumque sicut volui commodatos adhibui.

Alterum enim magister sociique collegii Cantabrigiensis ad Sancti Petri domum perlustrandum mihi tradiderunt, in hospitium per 5 hebdomades aedium suarum recepto iucundissimum. Alterum operis codicem, illo vel meliorem, quum otii tempus iam defecisset, inandita fere in Anglia benignitate a collegii Balliolensis Oxoniensis magistro sociisque ultra mare transmissum accepi, ut domi eo uterer. Quibus viris clarissimis et amicissimis opus nostrum dedicavi meritissimas eis gratias laete libenter relaturus.

Postea codices Parisienses quoque liberalitate bibliothecarii imperialis Francici et Borussici regï ministerii non sine magno commodo nactus sum. In his libris multa quidem deprehendi emendata atque aucta, multa, quae dubia fuerant, confirmata. Itaque opus tandem a mendis atque lacunis liberatum restituere licuit ita ut Alberti verba integra fere nec nisi perpaucis locis obscura habeas.

Summopere vero et ipse orthographia quum alio- 
rum verborum tum nominum plantarum perturbatus sum. Qua in re quum codices nec sibi nee inter se satis congruerent, tandem contigit, quam rem desponderat Meyer, ut codices duo Alberti ipsius manu exaratos, Coloniae usque asservatos exstare audirem, quorum alter historiam animalium continens quum veram Alberti orthographiam tum plurima plantarum nomina per totum opus dispersa praebebat. Quae summo negotio singula a me excerpta et in notis et in indice rerum habebis. Quo negotio perfecto facile intellexi nec illun, quem e codice Basileensi receperat Meyer scribendi modum, verum Alberti modum esse, nec Albertum ipsum de modo, cum quo nomina vel latina vel barbara scriberet, sibi satis constitisse, qui exempli gratia hic jusquiamum illic hyoscyamum dixit, ita ut caute tantum nomina ex animalium historia deprompta operi nostro inserenda essent. Minutias igitur Albertus verborum orthographiam credidisse videtur. Quare neminem fore spero, qui reprehendat, quod Meyeri vestigia relinquens, in libro nostro non studui ipsius Alberti orthographiam ex opere illo autographo frustillatim quasi conrodere. Laborem enim quamvis gravem non recusassem nisi timuissem, ne orthographia Alberti botanicis similibusque lectoribus incommodior futura esset, quam commoda eis, qui linguae historiam et grammaticam curant. His ut consulatur necesse erit, historiam illam animalium edi, sicut in Coloniensi libro ipsius Alberti manu exarata est.

Itaque usitatam per totum opus restitui orthographiam nec nisi nominibus plantarum vocibusque paucis singularibus formas veteres aut codicibus aut Alberti autographo proditas reliqui, easque in notis at- 
que indice rerum enotavi. Praeterea orthographia et grammatica Alberti non multum differt, id quod consentaneum est, ab ea qua coaevi rius usi sunt. Siquem vero opus erit quasi elementa dictionis Albertinae edoceri, is haec potissimum suadeo ut recordetur: ut cum coniunctivo atque accusativum cum infinitivo paene ignotum credes Alberto qui talia voce quod saepissime indicat; voces quod quia quoniam Albertus quidem aliquatenus, codices vero vix distinguerunt, quare de eis saepius ambigimus; participiis saepissime vario atque barbaro modo usus est e. g. est habens = est qui habet; infinitivus teutonico more substantivi dignitatem obtinet e. g. dans esse = quae dat existentiam I 7, est inveniri $=$ potest inveniri, distare facit deficere 165 ; coniunctivus plerumque res dubias falsasve indicat, nec coniunctiones certo modo sequitur; voces hic is ille iste more linguarum recentium saepissime atque promiscue adduntur, ita ut saepius fallatur lector; comparativus pro superlativo saepissime e. g. nobilior, quae VI 46, maiores omnium VI 141, fortius quod est in eo VI 425, prae omnibus peior VII 41.

De dictione Alberti vero verba addam, quibus quondam Bernardinus Plumatius Veronensis, logica Alberti opera editurus ${ }^{1}$ usus est: „hic doctor fundatissimus Aristotelicis verbis utitur tanquam suis et ea propter difficilis inordinatus obscurus et bar-

1 Editio haec impressa est amno 1506 Venetins ab heredibus Octaviani Scoti. Incipit: Ista sunt opera Alberti magni ad logican pertinentia, exhibet in fol. 176 : commentum super libris priorum analecticorum Aristotelis sumptum ex originali ncripto propriis manibus oudsdem Albea. 
bariem quandam sapere videtur. Siquis tamen absque omni livore doctrinam eius recte consideraverit: non solum inveniet hunc solertissimum interpretem Aristotelicos sensus enodare, sed singula eius verba exponere et considerate vel (ut dicunt) ponderatissime declarare, dubitationes cum questionibus ac digressionibus iuxta locorum exigentiam nullatenus omittendo, quapropter non solum expositor absque omni confusione vocandus est, sed distinctissimus interpres ac lucidissimus plus quam commentator." - Haec Bernardinus, qui profecto rem acu tetigit.

Superest ut viris doctissimis et celeberrimis gratias agamus, qui vel Meyerum vel meipsum libenter consilio et opera et aere adiuverunt, ut disquisitiones varias atque longinquas, quas opus postulabat, perficere potuerimus.

Dabam ex horto botanico Academiae Hildensis.

Idibus Septembribus anni 1866.

Carolus Jessen. 